\title{
The Regression Equation of Oxygen Content and Temperature to End Point of Bath Based on Exhaust Gas Analysis
}

\author{
Weiqing Huang, Yanxia Liu, Zhongqi Dong, Bing Yang \\ Hebei College of Industry and Technology, Shijiazhuang 050000, China
}

Keywords: mass spectrograph; converter; the off-gas.

\begin{abstract}
The off-gas of BOF is measured by mass spectrograph on-line and forecasting the refining process and end-point on time with the off-gas analysis. The results have shown that it is estimated the index model is applicable for forecasting carbon content of smelting end point; the cubic model is applicable for reflecting carbon content in molten pool at during smelting anaphase.
\end{abstract}

\section{Introduction}

This paper from the dynamic perspective, using mass spectrometry acquisition to the furnace gas online detection, the regression equation established pool of endpoint oxygen content and temperature, and use the test to verify the results and discussion for the regression equation, which aims to provide valuable guidance for the smelting process of reality.

\section{Study on the conditions and methods}

Analysis system used for VG Prima Delta B magnetic fan type process mass spectrometer imported from the British ONIX Danieli Corus company. The mass spectrometer for analysis of multi index system, principal component analysis for $\mathrm{CO}, \mathrm{CO} 2, \mathrm{O} 2$, N2, H2, Ar, He etc.. Mass spectrometer with material ion mass to charge ratio as a criterion for qualitative and quantitative analysis. Molecules all matter has a fixed quality, therefore, theoretically speaking, mass spectrometer is a kind of "universal" instrument. Its characteristics are fast analysis, component analysis, high accuracy. These are required to smelting cycle is short for the characteristics of the steelmaking process control.

\section{The establishment of mathematical model}

\section{The establishment of regression equation of $w[0]$}

In solving practical problems, generally do not know in advance the respective variables and dependent variables between the function form, especially in solving multivariate problems. But the regression equation is equation the coefficients, rather than the form of the equation, therefore, must be pre assumes a form of the equation can be evaluated in the actual calculation and analysis. To determine the relationship between type [5-7] usually function between each variable by using the following two ways:

1) to determine the function of relationship types between each variable with professional knowledge and practical experience;

2) to estimate the function of the form through the shape distribution scatter diagram.

Based on the above idea, considering the factors influencing the $\mathrm{w}[\mathrm{O}]$ at the end of the end of $\mathrm{w}[\mathrm{C}], \mathrm{T}, \mathrm{w}[\mathrm{P}], \mathrm{as}, \mathrm{w}[\mathrm{Mn}], \mathrm{w}[\mathrm{O}]$ respectively will end scatter of these elements, Figure 2, 3 shown. 


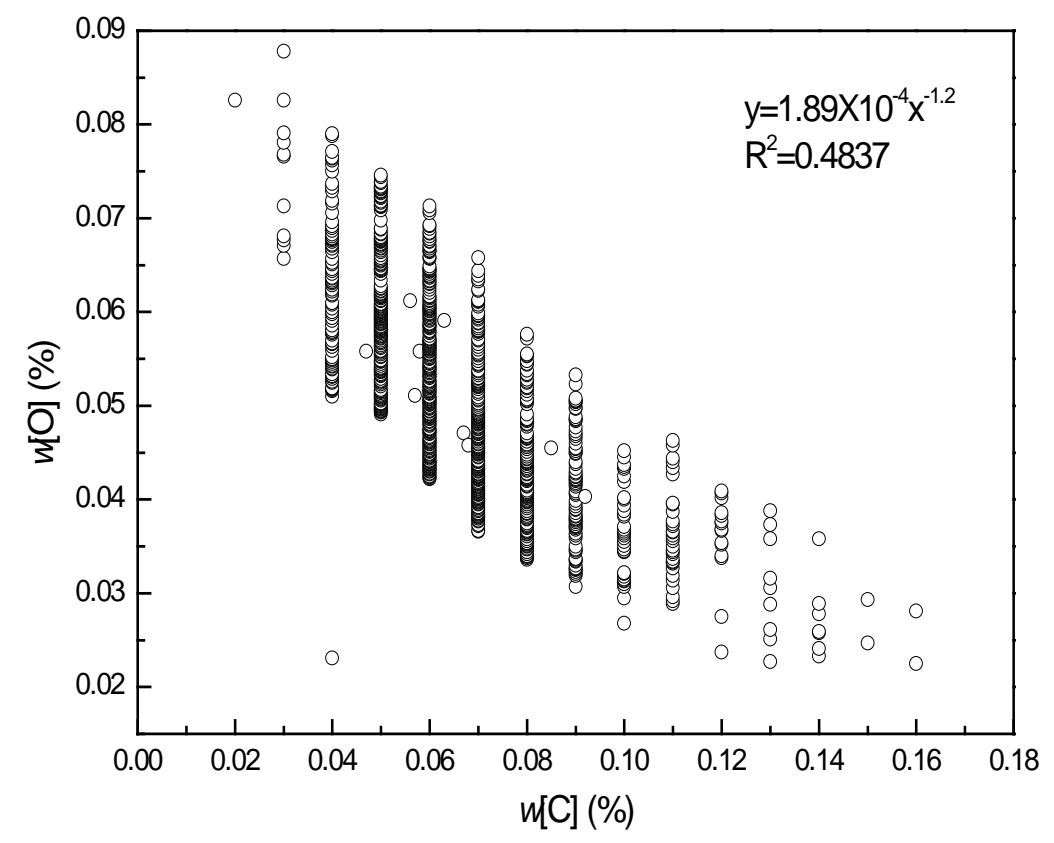

Fig. 2 The relationship between $w[\mathrm{O}]$ and $w[\mathrm{C}]$

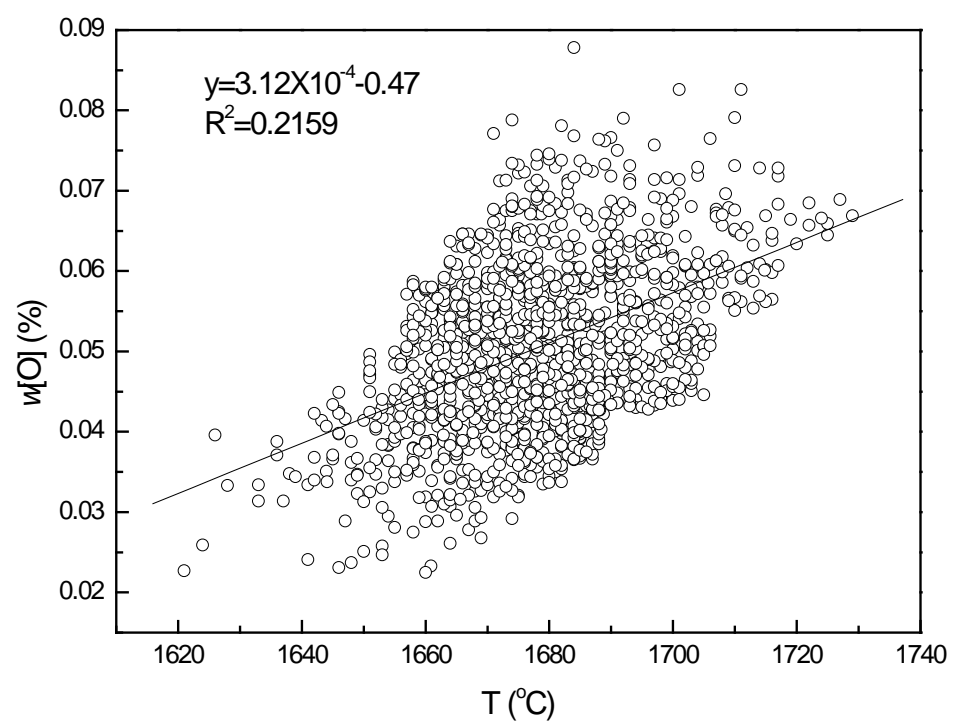

Fig. 3 The relationship between $w[\mathrm{O}]$ and $\mathrm{T}$

From Fig. 2, 3 can be seen, the end of w[O] increased with the finish of w[C] rapidly decreased, there is a negative exponential relationship between them, the relationship type is $w[O]=1.89 \times 10-3$ $\mathrm{w}[\mathrm{C}]-12$; increase with the end temperature, that is a positive linear correlation, the relationship type is $w[C]=3.12 \times 10-4 \mathrm{~T}-0.47$; because the $w[O] \mathrm{w}[\mathrm{P}]$, with $\mathrm{w}[\mathrm{Mn}]$ rules is not strong, so it is tentatively scheduled for a linear relationship, and then adjusted in the regression process. Therefore, the initial regression equation for $w[\mathrm{O}]$ :

$$
w[\mathrm{O}]=a_{0}+a_{1} w[\mathrm{C}]^{-1}+a_{2} \mathrm{~T}+a_{3} w[\mathrm{P}]+a_{4} w[\mathrm{Mn}]
$$


In the formula,w[O]- the endpoint oxygen content,\%; $w[\mathrm{C}]$ - carbon content, \%; T-end temperature, ${ }^{\circ} \mathrm{C} ; w[\mathrm{P}]$ - end phosphorus content, \%; $w[\mathrm{Mn}]$-final manganese content, $\%$.

\section{The establishment of regression equation of $T$}

$\mathrm{T}$ regression equation and $\mathrm{w}[\mathrm{O}]$ regression equation to establish the same process, taking into account the factors influencing on the end of $\mathrm{T}$ are mainly the end of $\mathrm{w}[\mathrm{C}]$ and $\mathrm{w}[\mathrm{O}]$ at the end of, respectively, T will do the scatter diagram of the two elements, as shown in Figure 4 and 5.

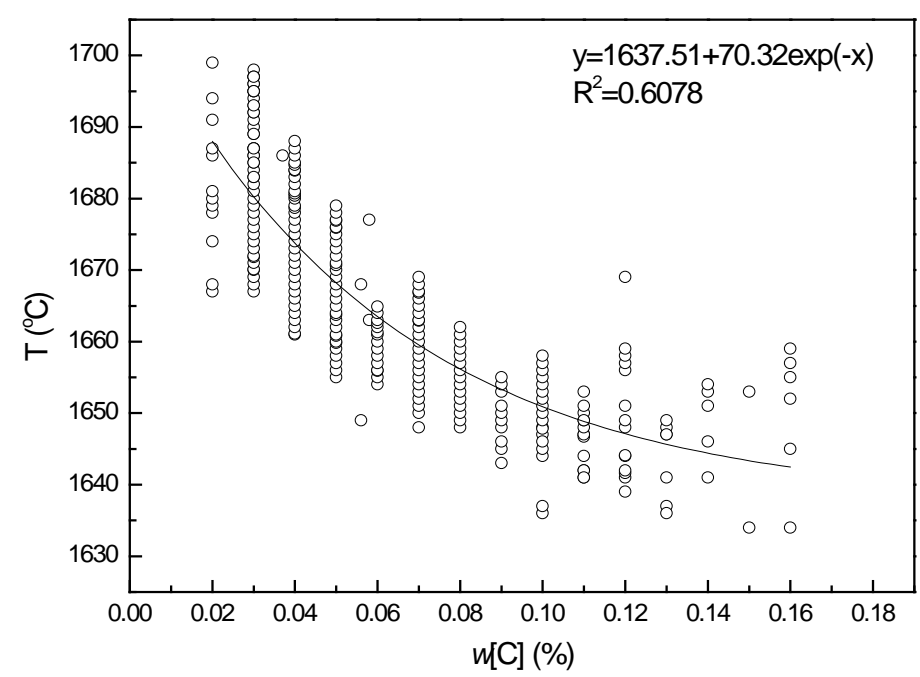

Fig. 4 The relationship between $\mathrm{T}$ and $w[\mathrm{C}]$

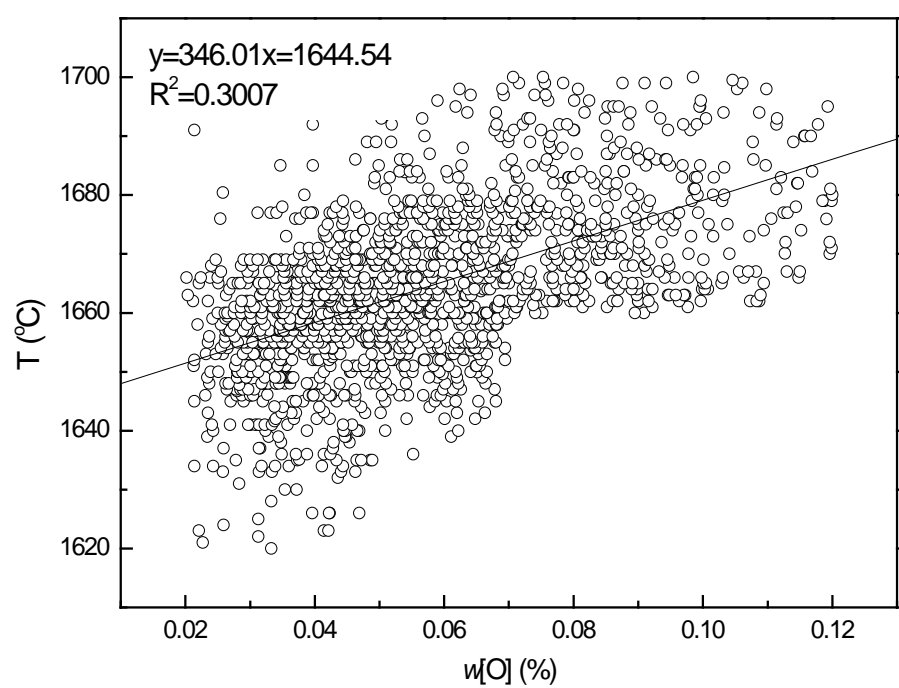

Fig. 5 The relationship between $\mathrm{T}$ and $w[\mathrm{O}]$

From Fig. 3.4, 3.5 can be seen, the finish temperature decreases with the increase of w[C] at the end of the $\mathrm{E}$, has a negative exponential relation between them, and the relation formula is $\mathrm{T}=1637.51+70.32 \exp (-\mathrm{w}[\mathrm{C}])$; increases with the increase of the end of $\mathrm{w}[\mathrm{O}]$, which is positively correlated with the end of $\mathrm{w}[\mathrm{O}]$, its relationship to $\mathrm{T}=346.01 \mathrm{w}[\mathrm{O}]+1644.54$. Therefore, the initial regression equation for $\mathrm{T}$ :

$$
\mathrm{T}=b_{0}+b_{1} \exp (-w[\mathrm{C}])+b_{2} w[\mathrm{O}]
$$

\section{The model prediction and the measured results and discussion}

\section{The endpoint oxygen content of the regression equation predicted and measured results}

The 1317 groups of data of Benxi Iron and steel converter production in the regression analysis of the data processing, from equation (1) began to use the search for "optimal" regression equation 
stepwise regression method. The size bias test value observation equation and the test value. In order to test the value of increasing equation as the first principle, to increase the partial test value of second principles, were to be adjusted in each variable equation, if the adjustment before the most remarkable in after the adjustment is still the most insignificant, the terms from the equation for eliminating. Excluding the impact of the end of $w[O]$ is not a significant amount, stepwise regression, finally get the following regression equation significantly:

$$
w[\mathrm{O}]=-0.022+1.787 \times 10^{-3} w[\mathrm{C}]^{-1}
$$

Verified by the remaining 500 furnace, the results shown in6 and 7.

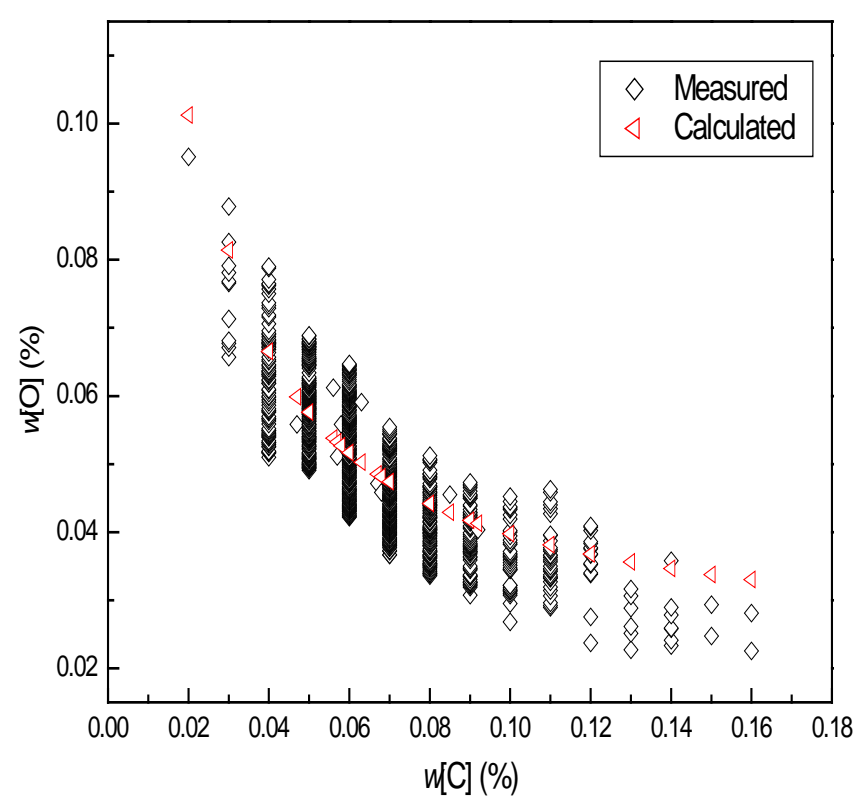

Fig. 6 Comparison between oxygen model calculation and industrial measurement

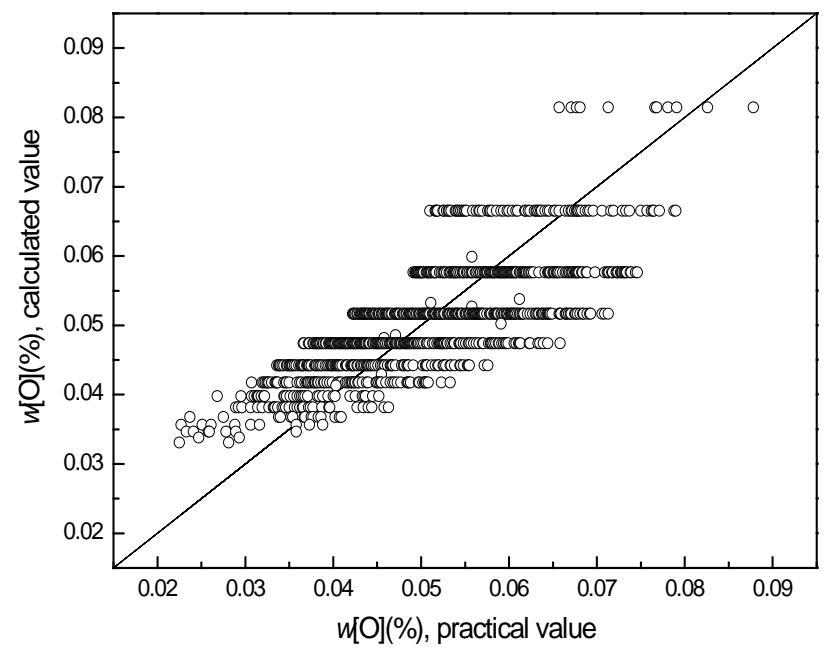

Fig. 7 Comparison between calculated values and practical data of end-point carbon content

Figure 6 is the $w[O]$ at the end of the measured variation with the end point $w[C]$ value and calculated value comparison diagram, Figure 7 is the end of w[O] comparison of the measured value and calculated value. Can be seen from the graph, using the (3) w[O] at the end of the calculated with the end of the change regularity of $\mathrm{w}[\mathrm{C}]$ are basically consistent with the measured 
values, equation (3) can accurately reflect the change rule of endpoint oxygen content with the end-point carbon content. The calculation of $w[O]$ value of the basic end located in the vicinity of the measured value, basically accord with the measured values, the variation rule and the measured value of the same. Therefore, type (3) can be used for more accurate prediction of endpoint oxygen content.

\section{The end-point temperature prediction and the measured results of the regression equation}

The 1491 groups of data of Benxi Iron and steel converter production data in the regression analysis, from equation (2) began to use the search for "optimal" regression equation stepwise regression method. The establishment of specific principles with the oxygen content of the regression equation, remove the influence on the final temperature is very small amount, stepwise regression, finally get the following regression equation significantly:

$$
\mathrm{T}=1430.92+231.27 \exp (-w[\mathrm{C}])+302.47 w[\mathrm{O}]
$$

Tested with the remaining 700 furnace, the results in Figure 8, shown in 9.

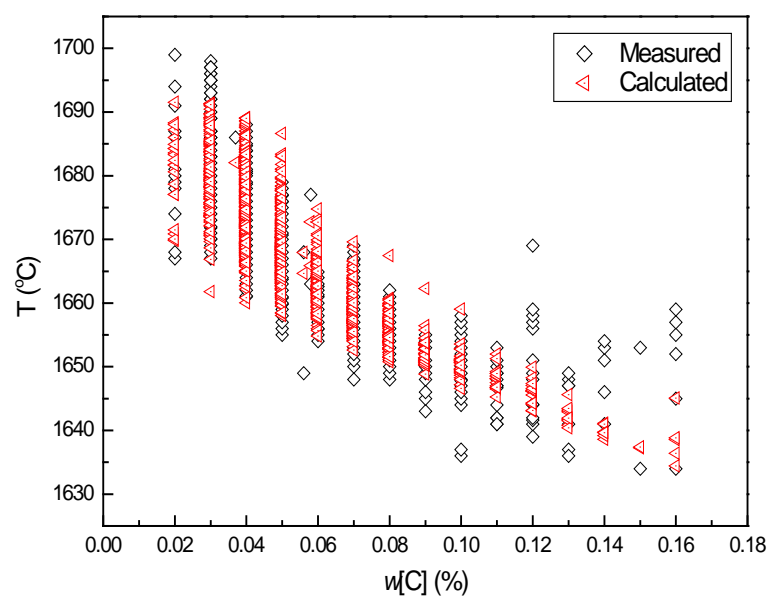

Fig. 8 Comparison between temperature model calculation and industrial measurement

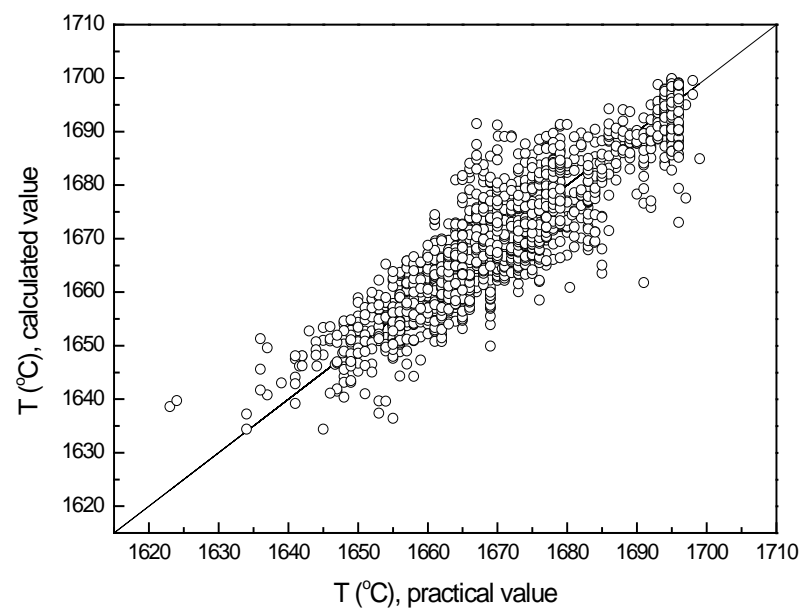

Fig. 9 Comparison between calculated values and practical data of end-point temperature

Figure 8 is the end of the measured temperature variation with w[C] at the end of the value and the calculated value of the comparison chart, figure 9 is the measured endpoint temperature value is compared with calculated values. Can be seen from the graph, the use of type (4) end temperature calculated with the destination $\mathrm{w}[\mathrm{C}]$ and variation of measured values of law are basically consistent, equation (4) can reflect the change rule with the end temperature of end point carbon content. In Figure 9, the calculation of end point temperature value basic distributed in the vicinity 
of the measured value, basically accord with the measured values. Therefore, type (4) can be used for more accurate prediction of endpoint temperature.

\section{Conclusion}

Using the formula of $w[O]=-0.022+1.787 \times 10-3 w[C]-1$ on the end of the oxygen content of the comparatively accurate prediction; using the formula $\mathrm{T}=1430.92+231.27 \mathrm{exp}(-\mathrm{w}[\mathrm{C}])+302.47 \mathrm{w}[\mathrm{O}]$ on the end-point temperature prediction more accurate.

\section{References}

[1] LIU Liu, YANG Qiang, ZHANG Chun-xia .Study on the Temperature Prediction Model of Molten Steel for RH Process [J], Journal of Iron and Steel Reseach, 2000, 12(2).

[2] Heinrich Rossner,Bodoreinhold,Guenter Urban. Automation of a 100-ton BOF[J],Iron and Steel Engineer,1970,47(8):70-76.

[3] Bernard Blum,John W Schwartzenberg,Frank C Lluxl. Control of Basic Oxygen Steelmaking [J],Iron and Steel Engineer,1967,44 (6): 111-119.

[4] Leitzke V A,Schroeder D L. A Closed-loop Control System for the Basic Oxygen Steel Process [J],Iron and Steel Engineer,1967,44 (8): :121-126.

[5] Diana L B,Jeffrey P D,Joseph N S. Process Control System for Dofasco's Ladle Metallurgy Facility[J].Iron and Steel Engineers,1990,(05):30-38.

[6] Kishimoto Y,Yamaguchi K,Sakuraya T. Decarburization Reaction in Ultra-low Carbon Iron Melting under Reduced Pressure[J].ISIJ International,1993,(03):391-399.

[7] Sano M,Han Y,Sawada T. Decarburization and Oxygen Absorption of Melten Iron of Low Carbon Concentration with Blowing Ar-O2 Mixture of Low Oxygen Pressure[J].ISIJ International,1993,(08):855-861. 